\title{
Teatro de fantoches como estímulo à leitura
}

\author{
Puppet theater as a stimulus to reading \\ El teatro de marionetas como estímulo a la lectura
}

Thainan Oliveira dos Anjos ${ }^{1}$, lan Soares Cardoso ${ }^{1}$, Cristiana Pires da Silva1, Larissa Luciana Pires Silva ${ }^{1}$, Dalberto Lucianelli Junior ${ }^{1}$, Felipe da Costa Soares ${ }^{1}$, Isabella Louise Morais de Sousa ${ }^{1}$, Jorge Lucas dos Santos Lima1', Luiz Felipe Façanha Ramos², Sarah Romênia Sousa Martins ${ }^{1}$, Ana Beatriz Costa da Silva ${ }^{1}$, Fernanda Nogueira Valentin ${ }^{1 *}$.

\section{RESUMO}

Objetivo: Abordar a experiência dos discentes de uma Universidade, sobre a prática da leitura através de recursos lúdicos como, o teatro de fantoches para crianças no ambiente escolar e hospitalar. Métodos: Tratase de um estudo descritivo desenvolvido por acadêmicos de uma Universidade do Pará na região do Xingú, na qual se pretendeu abordar a dinâmica "Teatro de Fantoches" realizado com 68 crianças no ambiente escolar e hospitalar em um município do Pará. Posteriormente foi coletada algumas informações através da aplicação de um questionário. As análises estatísticas foram realizadas pelo teste Pearson Chi-Square. Resultados: As informações coletadas durante as atividades evidenciaram que as histórias contadas ludicamente em forma de fantoches tiveram uma relação positiva entre as crianças independente dos dois ambientes. A maioria das crianças da escola são incentivadas a leitura e os seus responsáveis leem para elas, já as crianças do hospital, não há um incentivo por parte dos familiares. Conclusão: Por meio das ações foi possível perceber a importância do estímulo a leitura através das histórias contadas e da utilização de fantoches, pois esse método estimula o interesse pela leitura de uma maneira que facilita a compreensão das crianças sobre os temas abordados.

Palavras-chave: Leitura, Estímulo, Fantoches.

\begin{abstract}
Objective: To approach the experience of students of a University, in the practice of reading through playful resources such as puppet theater for children in the school and hospital environment. Methods: This is a descriptive study developed by academics from a University of Pará in the Xingú region, in which it was intended to approach the dynamic "Puppet Theater" performed with 68 children in the school and hospital environment of a municipality in Pará. Posteriorly, some information was collected through the application of a quiz. Statistical analyzes were performed using the Pearson Chi-Square test. Results: The information collected during the activities showed that the stories told playfully in the form of puppets had a positive relationship between the children regardless of the two environments. Most children at school are encouraged to read and their parents read to them, while children at the hospital, there is no incentive on the part of family members. Conclusion: Through actions it was possible to perceive the importance of stimulating reading through the stories told and the use of puppets, as this method stimulates the interest in reading in a way that facilitates children's understanding of the topics covered.
\end{abstract}

Keywords: Reading, Stimulation, Puppets.

\section{RESUMEN}

Objetivo: Abordar la experiencia de los estudiantes de una Universidad, sobre la práctica de la lectura a través de recursos lúdicos como el teatro de marionetas para niños en el ámbito escolar y hospitalario. Métodos: Se trata de un estudio descriptivo desarrollado por académicos de una Universidad de Pará en la región de Xingú, en el que se pretendía abordar la dinámica "Teatro de Marionetas" realizada con 68 niños en el ámbito escolar y hospitalario de un municipio de Pará. Posteriormente, se recopiló cierta información mediante la aplicación de un cuestionario. Los análisis estadísticos se realizaron mediante la prueba de chi-

1Universidade Federal do Pará (UFPA), Altamira - PA. *E-mail: fer_valentin@yahoo.com.br

¿Universidade Federal do Amapá (UNIFAP), Macapá - AP

SUBMETIDO EM: 11/2020

ACEITO EM: 12/2020

PUBLICADO EM: 2/2021 
cuadrado de Pearson. Resultados: La información recopilada durante las actividades mostró que las historias contadas de manera lúdica en forma de marionetas tenían una relación positiva entre los niños independientemente de los dos entornos. A la mayoría de los niños de la escuela se les anima a leer y sus tutores les leen, mientras que los niños del hospital, no hay incentivo por parte de los familiares. Conclusión: A través de las acciones se pudo percibir la importancia de estimular la lectura a través de los cuentos contados y el uso de títeres, ya que este método estimula el interés por la lectura de una manera que facilita la comprensión de los niños sobre los temas tratados.

Palabras clave: Lectura, Estimulación, Marionetas.

\section{INTRODUÇÃO}

O nascimento da leitura ocorreu pela necessidade de evolução do homem, na qual os símbolos precisavam ser entendidos e interpretados. Dessa forma, a leitura tornou-se cada vez mais indispensável no dia-a-dia da humanidade. A aprendizagem da leitura, geralmente se inicia na infância, período que compreende desde o nascimento até os doze anos de idade incompleto, de acordo com o Estatuto da Criança e Adolescente (BRASIL, 1990). As crianças são compreendidas como sujeitos únicos, cidadãs que tem direitos, potencialidades e necessidades (GAÍVA MAM e PAIÃO MRRS, 1999).

Detendo-nos agora um pouco mais acerca da influência de nossa visão de criança na importância de sua alfabetização, percebemos que é necessário compreender como a cultura contribui para o desenvolvimento das relações e atitudes sociais relativas às práticas de leitura junto à criança. Assim, quanto mais cedo se inicia esse processo mais rápido será criado o hábito e o gosto pela leitura, tornando-se importante no desenvolvimento e no processo de aprendizagem da criança, transformando-a em um agente social e integrante da cultura (ZILBERMAN R, 1984; MOREIRA PR, 2017).

Ao passo que a relação da leitura com a criança tem efeitos positivos, em contrapartida, a televisão, na maioria das vezes influência de forma negativa os filhos dentro de casa, como a perda da imaginação e do incentivo à leitura. De acordo com o documentário "Criança, a Alma do negócio", o IBGE aponta que as crianças brasileiras são as que passam mais tempo na frente da televisão no mundo, em média diária de 4 horas e 51 minutos (RENNER E e NISTI M, 2008).

Atualmente, a televisão é o meio digital menos referido pelas crianças, de acordo com Soares AMSB et al. (2019), os smartphones e tablets têm se tornado objetos de uso constante em crianças de 0 à 6 anos de idade, sendo consideras fonte de lazer. A utilização das tecnologias digitais com internet pode trazer benefícios como uma ferramenta de aprendizado, no entanto, o uso rotineiro e sem o devido reconhecimento educativo oferece também, para as crianças, certos riscos e exposições, e menor estímulo as habilidades e competências das mesmas (BRITO R e RAMOS A, 2017; OLIEMAT E et al., 2018).

Diferentemente dessas tecnologias, a leitura serve como instrumento para construção do conhecimento e auxilia na aprendizagem, socialização, criatividade, expressão das ideias, interpretação e criticidade. Para Barbosa JJ (1990) ler pode ser considerado uma atividade extremamente complexa e pessoal. Sendo assim saber ler constitui o resultado de toda uma educação, que nunca pode se dar por terminada. Contudo devese ter cuidado para que tal processo não se torne uma tarefa, onde ao fechar nela mesma, torne a escrita um processo mecânico e sem vida. Assim, antes que o sujeito domine a escrita precisa aprender o processo de significação entre a palavra falada e os objetos concretos (CORTI AP et al., 2011).

Segundo Vygotski LS (1991), a construção do conhecimento é dialético e implica na compreensão material e histórica da realidade na qual o sujeito está inserido. Nessa direção criar estratégias que possibilitem um manejo mais efetivo de instrução de interpretação da realidade vivenciada pelo sujeito e sua expressão oral, é de grande importância para a aquisição da escrita. Nos tempos do universo infantil, alguns aplicativos educativos utilizam imagens e vídeos interativos que estimulam as crianças no desenvolvimento da alfabetização de maneira divertida, construindo sua própria cultura (MARTENS M et al., 2018).

Outra alternativa interessante são os contos e histórias, que vêm sendo usados terapeuticamente, como uma estratégia para ensinar a ler com prazer, desenvolvendo habilidades de atenção, memória, expressão oral, afetiva e imaginação (O'HARE J, 2005; NILES RP e SOCHA K, 2014). Assim, o lúdico é uma ferramenta 
indispensável na educação, para que a criança desenvolva criatividade, iniciativa e autonomia, como também desenvolver-se socialmente e cognitivamente, além de adquirir conceitos que a possibilitam utilizar o pensamento lógico distinguindo a fantasia e a realidade (DE ASSIS MR, 2017). Além disso, Santos RM e Zatera LCS (2019) em seu estudo diz que a arte de contar história para crianças no ambiente hospitalar contribui para o aprendizado dos pacientes e torna-se possível ofertar-Ihes momentos de descontração, alegria e diversão podendo amenizar os traumas da internação.

Pelo fato da infância ser o período próprio da ludicidade, utilizou-se tal recurso neste projeto, pois, contar histórias vai muito além do entretenimento, por meio delas se enriquece as experiências infantis e desenvolve diversas formas de linguagem, amplia o vocabulário, ajuda na formação do caráter, e no desenvolvimento da confiança e do imaginário (SANTOS RM e ZATERA LCS, 2019).

Assim, o objetivo do trabalho foi abordar a experiência dos discentes em uma Universidade sobre prática da leitura através de recursos lúdicos como, o teatro de fantoches para crianças no ambiente escolar e hospitalar, para despertar o interesse de professores, equipe hospitalar e familiares à utilizarem essa ferramenta pedagógica, com o intuito de criar estratégias de incentivo à leitura que auxilie na aprendizagem das crianças, bem como promover mais ações de educação lúdica infantil, além de proporcionar momentos agradáveis entre as crianças e os discentes acadêmicos.

\section{MÉTODOS}

Trata-se de um estudo descritivo desenvolvido por acadêmicos de uma Universidade do Pará, na qual se pretendeu abordar a dinâmica "Teatro de Fantoches" para as crianças no ambiente escolar e hospitalar. Para a execução das atividades extensionistas, participaram oito alunos de medicina, dois alunos de especialização em Atenção Básica e Saúde da Família, dois docentes e 68 crianças entre outubro e novembro de 2019. As crianças participantes eram escolares (n. 57), com idades entre 6 a 8 anos de idade (jardim Il e primeira série), e crianças entre 6 a 10 anos de idade que estavam internadas em um hospital público (n. 11), ambos de um município do Pará, na região do Xingú.

Durante o projeto de extensão foram realizadas 4 ações educativas em cada ambiente (escola e hospital), sendo apresentadas uma história por encontro. Os gêneros literários utilizados foram fábulas e contos: 0 velho cão de caça de Nicéas de Romeo Zanchett; A cigarra e a formiga de Esopo; O patinho feio de Hans Christian Andersen; A galinha dos ovos de ouro de Ruth Rocha.

Posteriormente foi coletada algumas informações para análise do impacto das ações através da aplicação de um questionário que abordava perguntas simples como: identificação, sexo e etnia; aspectos relacionais da criança e aspectos relacionados à leitura.

A coleta de dados foi realizada com a aprovação do comitê de ética número CAAE: 34571220.6.0000.0018 (Plataforma Brasil). As análises estatísticas referentes as respostas coletadas foram realizadas pelo programa Statistical Package for the Social Sciences (SPSS 23).

Os dados contínuos foram apresentados em média e desvio padrão. Para os testes foi adotado um valor de $p<0,05$ como indicativo de significância. Para as análises categóricas, elas foram expressadas em proporções e foram analisadas pelo teste Pearson Chi-Square (Qui-quadrado).

\section{RESULTADOS E DISCUSSÃO}

A primeira fase do projeto consistiu em leitura de artigos e revisão bibliográfica; capacitações pelo coordenador do projeto e orientação para todos os integrantes quanto ao estímulo da leitura e do desenvolvimento cognitivo; confecção dos fantoches e dos cenários. À medida em que se retirou dúvidas quanto a informação provinda do referencial teórico pode-se delinear melhor as ações, escolher os contos mais adequados e discutir como seria a confecção dos fantoches e como os teatros deveriam ser abordados com as crianças, sempre com a preocupação de ter uma moral da história no final, a qual pudesse ser discutida com as crianças. 
A equipe elaborou um único cenário utilizado em todas as histórias, sendo realizado apenas pequenas alterações quando necessário, e confeccionou fantoches de acordo com os personagens de cada história abordada. Os fantoches foram confeccionados pelos próprios discentes com materiais simples: EVA, cola, glitter, caixa de papelão, caixa de leite, papel cartolina e TNT. Também foi discutido a importância de trabalhar com um tema atual e que pudessem abordar o público infantil através de um material didático. Assim foi decido trabalhar com o bullying, caracterizado pela violência física e/ou psicológica, de forma intencional e continuada, de certo(s) indivíduo(s) contra outro(s) indivíduo(s), sem motivo claro. Assim, resolvemos confeccionar uma história em quadrinhos para narrá-la através de imagens desenhadas e texto interrelacionados, incentivando a crianças a buscar também outros tipos de leitura.

$\mathrm{Na}$ segunda fase buscou-se facilitar a interação das crianças com a equipe de estudantes, a professora na escola e o acompanhante da criança no hospital criando um ambiente de descontração. Durante as ações, foi realizada a leitura dos contos infantis para as crianças e em seguida a encenação por meio de fantoches dos mesmos contos. Logo depois teve momentos interativos com perguntas acerca das histórias pós leitura e encenação. Pais, professores e acompanhantes também foram orientados sobre a importância do estímulo a leitura e as crianças receberam posteriormente a história em quadrinhos.

A terceira fase compreendeu a discussão dos resultados das ações com os alunos de graduação e pósgraduação; depois a reunião final e finalização dos relatórios. Nas filmagens realizadas durante as ações, pode-se descrever que, nas histórias contadas de forma lúdica com fantoches, foi possível promover momentos prazerosos e significativos de interação e diálogo entre os personagens e as crianças, as quais se sentiam motivadas, interessadas e dispostas a ouvir nossas histórias. Dessa forma, a maioria dos alunos apresentaram mudanças de comportamento social, como expressões de sorriso, comunicação, risadas, interação com as outras crianças e com os fantoches; além de cantar as músicas que foram inseridas durante o teatro de fantoches; diferentemente quando comparado com as histórias apenas lida, onde os alunos permaneceram quietos, desatentos e indiferentes e apáticos.

Nesse sentido, Dantas OMdS, et al. (2012) confirma que, essa ludicidade proporciona a criação de momentos prazerosos que estimulam a imaginação e a criatividade possibilitando às crianças idealizar situações, personagens e falas, contribuindo para o aprimoramento da oralidade nos momentos em que a criança faz a fala dos fantoches ou interage com eles, além de incentivar maior interação com seus pares de forma espontânea e descontraída.

Por meio das intervenções pode-se incentivar o interesse da criança pela leitura, transformando esses momentos em hábitos prazeroso, bem como, proporcionar um ambiente mais afetivo para as crianças na escola e para os pacientes internados, diminuindo o estresse da sala de aula e também da internação com o intuito de ajudar na recuperação das crianças através de atividades lúdicas. Pode-se perceber também que foi estimulado uma interação prazerosa entre a criançada da escola e com a professora; assim como do hospital com os acompanhantes responsáveis.

$\mathrm{Na}$ escola as crianças questionavam as atitudes dos fantoches para professora de acordo com a história, como por exemplo, porque o velho cão era maltratado, porque o patinho negro era feio e desprezado, se a formiguinha não trabalhar, não vai ter comida no inverno? ... e assim por diante. No hospital as crianças ficavam maravilhadas com a encenação, alguns chegaram até dançar no colo de seus familiares, esquecendo por instantes que estavam num ambiente hospitalar. A maioria das crianças dialogou com a equipe de estudantes e algumas delas levaram para casa os fantoches utilizados no cenário, dizendo que iria replicar a história em casa para seus familiares. Assim, percebemos que nossa prática de contar história com fantoches era dotada de sentido para as crianças e capaz de cativar e prender o interesse delas.

Dessa forma, Singer E (2015) ratifica que as atividades que envolvem ludicidade permitem ao indivíduo a integração dos pensamentos e sentimentos, estimulando a sensibilidade e fazendo com que a criança vivencie momentos de prazer e alegria, pois a afetividade é estimulada por meio de vivencias, estabelecendo assim, vínculos de afeto uns com os outros. Assim, através das histórias abordadas conseguimos transmitir mensagens com uma visão crítica e com uma moral onde se buscou explorar atitudes básicas como o respeito, incentivar a importância do trabalho em equipe considerando as diferenças e limitações de cada indivíduo e promover as atitudes boas que devemos realizar na sociedade e estimular um bom convívio entre todos. 
Além desses objetivos alcançados, no hospital, ao se utilizar fantoches, as crianças se divertiram e dessa maneira se quebrou a ideia do hospital como um ambiente que simplesmente cuida de doentes ou de paciente limitado ao leito sem ter um momento de lazer, de brincar e se divertir, dessa forma diminuiu o estresse proporcionado pelo ambiente hospitalar favorecendo uma melhor recuperação. Entretanto, algumas atitudes das crianças nos fizeram refletir, quando algumas delas nos perguntaram se tínhamos livros para doar durante a ação. Realmente a ideia era de realizar uma campanha para arrecadação de livros infantis para serem distribuídos durante as ações, porém, não foi possível, pois as atividades foram interrompidas devido a pandemia. Outra dificuldade foi no Hospital, pois, encontramos poucas crianças internadas, além da faixa etária ter variado entre 2 a 10 anos, portanto, tivemos que nos limitar apenas às crianças a partir de 6 anos para realizar o questionário o que diminuiu ainda mais o $n$ amostral.

Em relação aos questionamentos realizados após as ações, percebemos que teve uma relação de 1:1 quanto ao sexo das crianças $\left(P=0,559\right.$ e qui-quadrado $\left(X^{2}\right)=0,341$, porém, referindo-se a etnia houve uma diferença entre os dois ambientes, tendo mais crianças brancas no ambiente escolar e mais pardas no ambiente hospitalar (Tabela 1).

Independente da diferença de etnia nos dois ambientes, estudos constatam que a etnia e os aspectos relacionados a educação envolvem diversos fatores, não devendo limitar às dificuldades escolares dos alunos apenas a assuntos de ordem familiar (PATTO MHS, 1992). Ademais, pais afro-americanos e hispânicos dão grande valor à educação, preocupados com questões educacionais, e têm aspirações para seus filhos iguais aos de pais não pertencentes a minorias (DRIESSEN G, et al., 2005; SPERA C, et al., 2009).

Tabela 1 - Etnia das crianças entre a escola e hospital.

\begin{tabular}{ccccc}
\hline \multirow{2}{*}{ Etnia } & \multicolumn{2}{c}{ Local } & \multicolumn{1}{c}{ Significância } \\
\cline { 2 - 5 } & Escola (\%) & Hospital (\%) & $\boldsymbol{P}$ & Pearson Chi-Square \\
\hline Branco & 37,9 & 0,0 & & \\
Indígena & 0,0 & 30,0 & 0,0001 & 21,668 \\
Negro & 15,5 & 10,0 & & \\
Pardo & 46,6 & 60,0 & & \\
\hline
\end{tabular}

Fonte: Anjos TO, et al., 2021.

Tanto no ambiente escolar e hospitalar, todas as crianças afirmaram ter boas relações com os colegas, educadores e equipe hospitalar, respectivamente. Quanto ao estímulo a leitura, 96,6\% das crianças são incentivadas no ambiente escolar pelos professores, em contrapartida no hospital apenas $10 \%$ dos pacientes são incentivados pelos acompanhantes no ambiente hospitalar $(P=0,0001),(X 2)=54,853$, demonstrando que não há estímulo de leitura em hospitais.

Dessa forma, percebe-se a importância de haver maior estímulo a leitura tanto em cenários educacionais como em hospitais. Na escola, a contação de histórias utilizada como atividade interativa e pedagógica mediada pelo educador contribui para o desenvolvimento infantil permitindo conhecer novas palavras, à usarem a imaginação, desenvolverem a oralidade, a criatividade e o pensamento crítico abrindo espaço para novas aprendizagens nas diversas disciplinas escolares. Já na pedagogia hospitalar, o estímulo à leitura e brincadeiras podem contribuir como uma fonte de prazer, conhecimento e emoção, bem como uma distração para as crianças internadas podendo amenizar os traumas da internação, portanto, deveriam fazer parte do tratamento, otimizando a intervenção e diminuindo o tempo de internação (OLIVEIRA LDB et al., 2009; RAFFAELLI R, 2010; DE SOUSA LO e BERNARDINO AD, 2011).

Em relação a compreensão das histórias (fábulas) e suas morais, ambas as crianças entenderam as histórias e seus ensinamentos independente do ambiente de interação (Tabela 2). Além disso, as histórias contadas ludicamente em forma de fantoches tiveram um efeito positivo entre as crianças independente do ambiente escolar ou hospitalar, mostrando que a maioria delas preferiram a ludicidade (Tabela 2).

Dessa forma Dantas AP et al. (2006) corrobora que, o teatro de fantoches como recurso lúdico para situações de ensino aprendizagem proporciona às crianças momentos prazerosos e divertidos que se tornam facilmente absorvidos. 
Tabela 2 - Avaliação das crianças quanto a leitura

\begin{tabular}{cccccc}
\hline & & \multicolumn{2}{c}{ Local } & \multicolumn{2}{c}{ Significância } \\
\cline { 3 - 6 } Leitura & Alternativa & $\begin{array}{c}\text { Escola } \\
(\%)\end{array}$ & $\begin{array}{c}\text { Hospital } \\
(\%)\end{array}$ & $\boldsymbol{P}$ & $\begin{array}{c}\text { Pearson } \\
\text { Chi- } \\
\text { Square }\end{array}$ \\
\hline Entendeu a história? & Não & 3,4 & 0,0 & 0,551 & 0,355 \\
\hline $\begin{array}{c}\text { Concorda com a } \\
\text { moral? }\end{array}$ & Sim & 96,6 & 100 & 0,867 & 0,286 \\
\hline Prefere lida ou & Sim & 1,7 & 0,0 & & 3,610 \\
Fantoche? & Lida & 61,4 & 90,0 & & \\
& Fantoche & 65,5 & 10,0 & & \\
& Os dois & 27,6 & 90,0 & & \\
\end{tabular}

Fonte: Anjos TO, et al., 2021.

Sobre a criança estar em processo de alfabetização, houve uma diferença entre o perfil das crianças de acordo com o ambiente. A maioria dos estudantes da escola sabem ler ou estão em processo de aprendizagem, diferentemente das crianças do hospital, com nível de alfabetização zero ( $P=0,001)$, quiquadrado $\left(X^{2}\right)=13,190$ (Figura 1). Quanto aos estímulos à leitura em casa, se há livros em sua casa, a grande maioria das crianças da escola são incentivadas a leitura $\left[P=000,1\right.$ e $\left.\left(X^{2}\right)=14,471\right]$ e os seus responsáveis leem para elas [0,099 e $\left.\left(X^{2}\right)=2,723\right]$, já as crianças do hospital, não há um incentivo por parte dos familiares à leitura (Figura 2 e Figura 3).

O nível de alfabetização das crianças e seu estímulo à leitura pelos seus familiares podem estar relacionados com a diferença entre os ambientes da escola, a qual é uma instituição privada e do Hospital considerado um serviço público, os quais podem ter contribuído para diferença socioeconômica das crianças participantes, que por sua vez pode ter favorecido negativamente nesses aspectos (RINDERMANN HJI, 2008). Pesquisas sobre a associação família-escola mostram que o nível de escolaridade e a capacidade de realização educacional de seus filhos também está relacionado com o ambiente acadêmico e recursos financeiros de seus pais (RINDERMANN HJI, 2008).

Figura 1 - Competências em leitura das crianças entre seis a dez anos de idade.

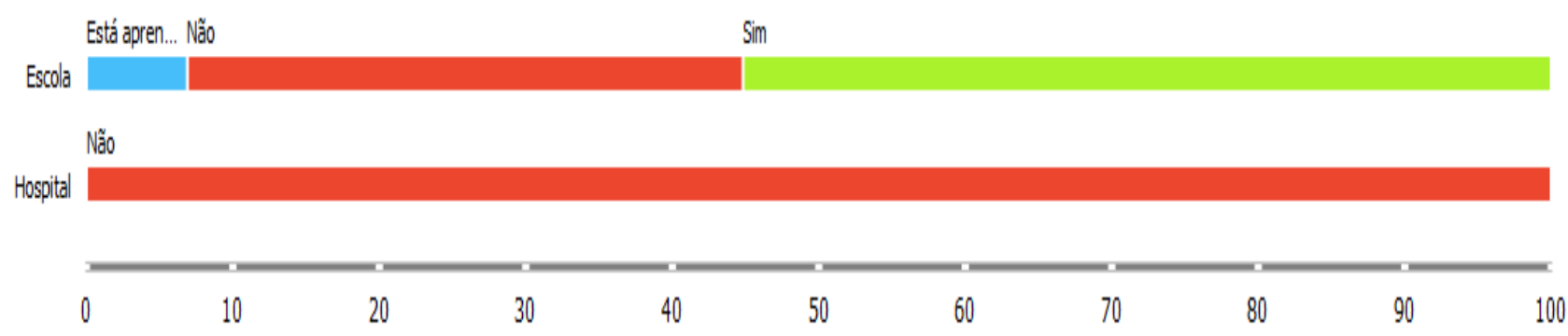

Fonte: Anjos TO, et al., 2021.

Figura 2 - Se há livros em suas casas e estímulo a leitura.

Nẵ ... Sim

Escola
Nลั๊
Nã̃i informado Sim

Hospital

$\begin{array}{lll}0 & 10 & 20\end{array}$

Fonte: Anjos TO, et al., 2021. 
Figura 3 - Se os responsáveis leem para as crianças

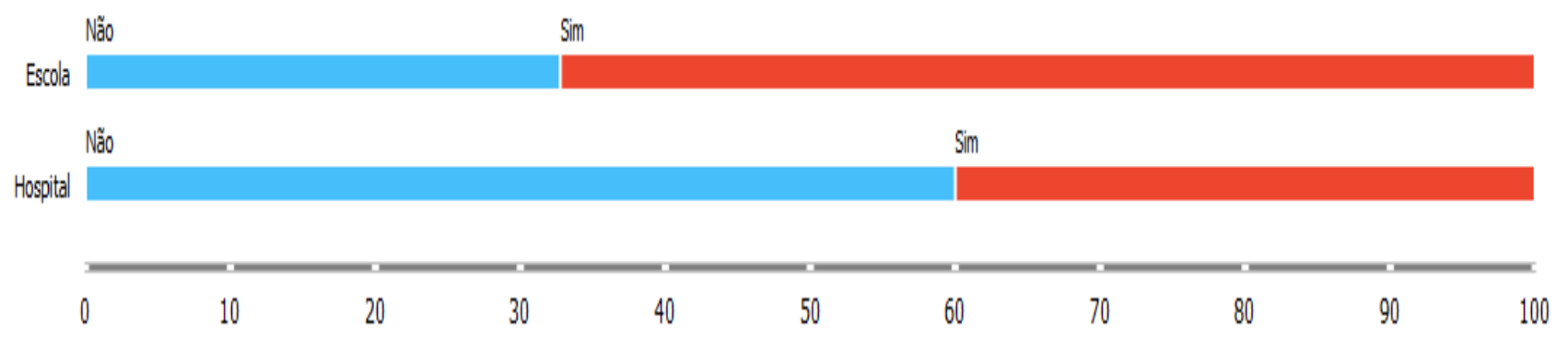

Fonte: Anjos TO, et al., 2021.

Referindo-se a interação das crianças com a televisão, smartphones e jogos, tanto as crianças da escola (94\%) quanto do hospital ( $80 \%$ ) disseram que assistem e jogam frequentemente $P=0,97$ e $(x 2)=2,753$.

Estudos indicam que a televisão e tecnologias digitais proporcionam efeitos negativos para o público infantil, se não forem supervisionados pelos pais, pois, promovem atitudes e comportamentos de passividade, privando as crianças de um tempo que poderiam utilizar para realizar outras tarefas que estimulem suas capacidades cognitivas, além de, promover ansiedade e compulsão (SEON-KYOUNG A e DOOHWANG L, 2010; BRITO R e RAMOS A, 2017; OLIEMAT E et al., 2018; DE ALVARENGA-DIAS FM et al., 2019).

\section{CONCLUSÃO}

Por meio das ações foi possível perceber a importância do estímulo a leitura através das histórias contadas e da utilização de fantoches, pois esse é um meio que chama a atenção das crianças e estimula o interesse pela leitura facilitando a compreensão das crianças sobre os temas. Após as intervenções, percebemos que ambos os grupos preferiram as histórias contadas por meio do teatro de fantoches do que as histórias apenas lidas. Quanto ao estímulo a leitura, constatou-se que somente na escola acontece tal prática. Outros resultados que corroboram são o do alto uso de televisão e jogos em ambos os ambientes. Sendo assim, destaca-se a importância de estimular a leitura infantil por meio de teatro de fantoches, de maneira lúdica, no ambiente escolar e hospitalar. Além de proporcionar momentos interativos com as crianças, as intervenções também proporcionam momentos agradáveis com toda equipe.

\section{AGRADECIMENTOS E FINANCIAMENTOS}

Agradecemos à Universidade Federal do Pará, campus de Altamira, ao Grupo de Estudo e Pesquisa em Saúde e Educação na Amazônia (GEPSEA) pela colaboração, pelos pesquisadores Rodrigo Silveira e Francisco Bruno Teixeira pela assistência técnica e pelo Eixo Transversal 2019 da PROEX pela bolsa extensionistas cedida.

\section{REFERÊNCIAS}

1. BARBOSA JJ. Alfabetização e Leitura. São Paulo: Coleção Magistério 20 Grau, 1990; 160 p.

2. BRASIL. 1990. Dispõe sobre o Estatuto da Criança e do Adolescente e dá outras providências. In Secondary Dispõe sobre o Estatuto da Criança e do Adolescente e dá outras providências (Secondary Brasil, ed.), Disponível em: http://www.planalto.gov.br/ccivil_03/LEIS/L8069.htm\#art266: Diário Oficial [da] República Federativa do Brasil, Brasília, DF, 16 jul. 1990.Acesso em: 05 jan. 2021.

3. BRITO R, RAMOS A. 2017. Tecnologia digital em ambiente familiar: o caso de crianças dos 0 aos 6 anos. In Secondary Tecnologia digital em ambiente familiar: o caso de crianças dos 0 aos 6 anos (Secondary Brito R, Ramos, A, eds.), https://repositorium.sdum.uminho.pt/simple-

search?query=Tecnologia+digital+em+ambiente+familiar\%3A+o+caso+de+crian\%C3\%A7as+dos+0+aos+6+anos: RepositóriUM.Acesso em: 20 out. 2020.

4. CORTI AP, et al. 2011. Caderno de Reflexões - Jovens de 15 a 17 anos do Ensino Fundamental. In Secondary Caderno de Reflexões - Jovens de 15 a 17 anos do Ensino Fundamental (Secondary Corti A P, et al., eds.), http://iipeoei.org/sites/default/files/bra-educacion_media.pdf\#page=75: Ministério da Educação.Acesso em: 20 out. 2020.

5. DANTAS AP, et al. Treatment of Trypanosoma cruzi-infected mice with propolis promotes changes in the immune response. Journal of ethnopharmacology, 2006; 103: 187-193.

6. DANTAS OMDS, et al. Teatro de fantoches na formação continuada docente em educação ambiental. J Educação e Pesquisa, 2012; 38: 711-726. 
7. DE ALVARENGA-DIAS FM, et al. Autismo virtual: as implicações do uso excessivo de smartphones e tablets por crianças e jovens. J Redin-Revista Educacional Interdisciplinar, 2019; 8: 1-11.

8. DE ASSIS MR. O Lúdico no Processo de Desenvolvimento da Imaginação e Criatividade na Criança. J EDUCAÇÃO E CULTURA EM DEBATE, 2017; 3: 113-130.

9. DE SOUSA LO, BERNARDINO AD. A contação de histórias como estratégia pedagógica na educação infantil e ensino fundamental. J Educere et Educare, 2011; 6: 1-15.

10. DRIESSEN G, et al. Parental involvement and educational achievement. J British educational research journal, 2005; 31: 509-532.

11. GAÍVA MAM, PAIÃO MRRS. O ser criança: percepção de alunas de um curso de graduação em enfermagem. J Revista Latino-Americana de Enfermagem, 1999; 7: 75-83.

12. MARTENS M, et al. Child-centered design: Developing an inclusive letter writing app. J Frontiers in psychology, 2018; 9: 1-14.

13. MOREIRA PR. 2017. A Importância da Leitura na Educação Infantil. In Secondary A Importância da Leitura na Educação Infantil (Secondary Moreira P https://www.researchgate.net/publication/321586571_A_IMPORTANCIA_DA_LEITURA_NA_EDUCACAO_INFANTIL : ReseartGate.Acesso em: 30 out. 2020.

14. NILES RP, SOCHA K. A importância das atividades lúdicas na educação infantil. J ÁGORA: Revista de divulgação científica, 2014; 19: 80-94.

15. O'HARE J. Puppets in education: process or product? Bloomington: Authorhouse, 2005; p.

16. OLIEMAT E, et al. The use of touch-screen tablets in early childhood: Children's knowledge, skills, and attitudes towards tablet technology. J Children, 2018; 88: 591-597.

17. OLIVEIRA LDB, et al. The hospital playroom as a factor in the promotion of child development: report of experience. J Journal of Human Growth, 2009; 19: 306-312.

18. PATTO MHS. A família pobre e a escola pública: anotações sobre um desencontro. J Psicologia USP, 1992; 3 : 107121.

19. RAFFAELLI R. Cadernos de Pesquisa Interdisciplinar em Ciências Humanas. 2010.

20. RENNER E, NISTI M. 2008. Criança, a alma do negócio. In Secondary Criança, a alma do negócio (Secondary Renner E, Nisti, M, eds.), Disponível em: https://www.youtube.com/watch?v=ur9Ilf4RaZ4\&t=369sMARIA FARINHA FILMES: publicidade, consumo e infância.Acesso em: 20 jun 2020.

21. RINDERMANN HJI. Relevance of education and intelligence at the national level for the economic welfare of people. 2008; 36: 127-142.

22. SANTOS RM, ZATERA, LCS. A arte de contar histórias para crianças em ambiente hospitalar. J Caderno Intersaberes, 2019; 8: 19-35.

23. SEON-KYOUNG A, DOOHWANG L. An integrated model of parental mediation: the effect of family communication on children's perception of television reality and negative viewing effects. J Asian Journal of Communication, 2010; 20: 389-403.

24. SINGER E. Play and playfulness in early childhood education and care. In Psychology in Russia: state of the art. Moscow, Russia: Russian Psychological Society, 2015; 27 p.

25. SOARES AMSB, et al. O uso excessivo de smartphones em crianças, adolescentes e jovens: sintomas ostemusculares auto referidos. J Health Sci Inst., 2019; 37: 246-250.

26. SPERA C, et al. Parental aspirations for their children's educational attainment: Relations to ethnicity, parental education, children's academic performance, and parental perceptions of school climate. Journal of youth, 2009; 38: $1140-1152$.

27. VYGOTSKI LS. A formação social da mente. São Paulo - SP: Livraria Martins Fontes Editora Ltda, $1991 ; 160$ p.

28. ZILBERMAN R. Leitura em crise na escola: as alternativas do professor: Mercado Aberto, 1984; $p$. 